\title{
IMPLEMENTASI ALGORITMA APRIORI TID UNTUK MENGETAHUI POLA PENJUALAN KERAMIK
}

\author{
Anri Muda Siregar ${ }^{1}$, Muhammad Syahrizal, ${ }^{2}$ \\ Program Studi Teknologi Informatika STMIK Budi Darma, Medan, Indonesia \\ Email: Regarandri13@gmail.com
}

\begin{abstract}
Abstrak
Pada PT. JUI SHIN INDONESIA Medan Deli dilakukan pengecekan penjualan keramik setiap satu tahun sekali, Jumlah keramaik yang dibutuhkan di PT. JUI SHIN INDONESIA Medan Deli begitu besar. interaksi penjualan yang selama ini, kurang baik, mengakibatkan penjualan keramik dan mutu pelayanan terhadap coustamermenurun. Penelitian ini mengharapkan untuk menganalisis gambaran beroperasi umum, penjualan keramik PT. JUI SHIN INDONESIA Medan Deli. Masalah yang sering dihadapi adalah barang tidak tersusun rapi dan tidak bisa dimamfaatkan untuk pengembangan sistem dan hanya dijadikan arsip di PT. JUI SHIN INDONESIA Medan Deli. Untuk mengetahui pola penjualan keramik, penjualan keramik selama ini kurang efektif karena data yang tersimpan dalam Microsoft Excel masih kurang baik sehingga memerlukan waktu yang lama apabila sewaktuwaktu gudang PT. JUI SHIN INDONESIA Medan Deli lain maupun Administrasi perusaahan melakukan pengecekan data.Untuk itu diperlukan suatu sistem yang dapat mempermudah pihak gudang dalam menganalisa data pnjualan keramik. Algoritma ini merupakan salah satu bagian dari association rule mining. metode ini bertujuan untuk mendapatkan aturan asosiasi atau relasi antar sekumpulan item. dengan menggunakan sietem aplikasi tool Tanagra untuk pengujian data transaksi penjualan keramik.
\end{abstract}

Kata kunci: Untuk Mengetahui Pola Penjualan Keramik Dengan Algoritma Apriori TID

\begin{abstract}
At PT. JUI SHIN INDONESIA Medan Deli is checking the sales of ceramics once a year. The amount of ceramics needed at PT. JUI SHIN INDONESIA Medan Deli is so big. The lack of good sales interactions has resulted in ceramics sales and the quality of service to the council going down. This research expects to analyze the general operating picture, ceramic sales of PT. JUI SHIN INDONESIA Medan Deli. The problem often faced is that goods are not neatly arranged and cannot be utilized for system development and are only used as archives at PT. JUI SHIN INDONESIA Medan Deli. To find out the pattern of ceramics sales, ceramics sales have so far been ineffective because the data stored in Microsoft Excel is still not good so it requires a long time if at any time the warehouse of PT. JUI SHIN INDONESIA Medan Deli and other company administrations do data checking. For that we need a system that can facilitate the warehouse in analyzing the sales data of ceramics. This algorithm is one part of association rule mining. This method aims to obtain the rules of association or relations between groups of items. by using the Tanagra tool application method for testing data on ceramic sales transactions.
\end{abstract}

Keywords: To Know the Pattern of Ceramic Sales Using the Aryri TID Algorithm

\section{PENDAHULUAN}

Menurut riandy dalam buku jurnalnya sistem informasi yang berjudul rancang bangun sistem informasi penjualan barang sebagai berikut Penjualan suatu usaha yang terpadu untuk mengembangkan rencana-rencana strategis yang diarahkan pada usaha pemuasan kebutuhan dan keinginan pembeli, guna mendapatkan penjualan yang menghasilkan laba. Penjualan dapat dilakukan dengan berbagai cara, ada penjualan yang dilakukan secara tunai dan ada yang dilakukan secara kredit.Penjualan tunai dilakukan apabila barang yang diberikan oleh penjual langsung saat barang tersebut diterima dan ini sudah umum dilakukan juga dianggap sebagat penjulan yang lazim, dan penjualan yang dilakukan secara kredit adalah merupakan hal tagihan yang timbul dari transaksi penjualan barang atau jasa, dan merupakan komponen besar dalam aktiva lancar [1]. PT. JUI SHIN INDONESIA merupakan satu-satunya perusahaan di bidang industri keramik dan granit di pulau Sumatera. Tujuan awal pendirian adalah untuk memenuhi pangsa pasar Sumatera dengan harga produk terjangkau dan pelayanan yang cepat, serta memuaskan. PT. JUI SHIN INDONESIA awalnya berproduksi dengan 3 lini produksi keramik pada tahun 2002, namun karena permintaan yang terus meningkat, perusahaan berkembang menjadi 7 lini produksi keramik dan 2 lini produksi granit. Selama ini data penjualan keramik pada PT. JUI SHIN INDONESIA tidak tersususun dengan baik oeleh karena itu data tersebut hanya berguna untuk arsip perusahan saja dan tidak dapat digunakan untuk pengembangan pemasaran. Dalam penjualan keramik pada PT. JUI SHIN INDONESIA di perlukan data mining untuk menentukan pola kommbinasi produk keramik. Data mining merupakan analisis data menggunakan tools Tanagra 1.4 dalam data mining untuk memprediksi.

\section{TEORITIS}

\subsection{Data Mining}

Data mining, sering juga disebut knowledge discovery in database (KDD), adalah kegiatan yang meliputi pengumpulan, pemakaian data historis untuk menemukan keteraturan, pola atau hubungan dalam set data berukuran besar. Keluaran dari data mining bisa dipakai untuk memperbaiki pengambilan keputusan di masa depan [5].

Dari defenisi-defenisi yang telah disampaikan, hal penting yang terkait dengan data mining adalah[5][6]:

1. Data mining merupakan suatu proses otomatis terhadap data yang sudah ada. 
2. Data yang akan diproses berupa data yang sangat besar.

3. Tujuan data mining adalah mendapatkan hubungan atau pola yang akan

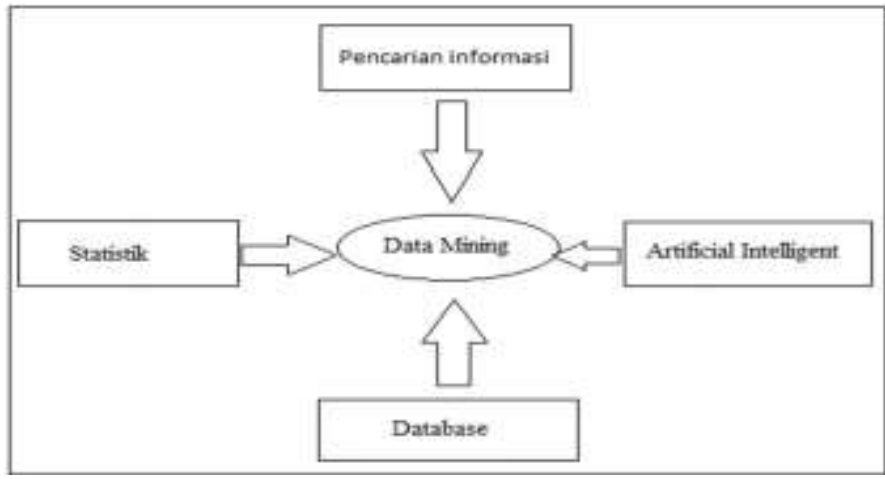

Gambar 1. Bidang Ilmu Data Mining

\subsection{Algoritma Apriori TID}

Algoritma Apriori TID adalah salah satu bagian dari association rule mining. Association rule mining merupakan salah satu teknik yang ada dalam penambangan data yang bertujuan untuk mendapatkan aturan asosiasi atau relasi antara sekumpulan item. Aturan asosiasi dapat diperoleh dari berbagai sumber data, di antaranya berasal dari basis data transaksional, gudang data, maupun dari tempat penyimpanan informasi yang lainnya. Pada umumnya data yang diolah bersifat homogen. Studi pertama tentang pencarian aturan asosiasi diperoleh dari itemset yang sering muncul secara bersama-sama[3].

Salah satu algoritma yang sering digunakan untuk pencarian aturan asosiasi adalah Apriori (Gunawan, dkk, 2016). Penting tidaknya sebuah aturan asosiasi dapat diketahui dengan dua parameter, yaitu support (nilai penunjang), yaitu persentase kejadian kombinasi item atau support count jumlah itemset yang muncul dalam sekumpulkan transaksi, dan confidence (nilai kepastian), yaitu kuatnya hubungan antar item dalam aturan asosiasi (J. Han.,et,al, 2012) Analisis asosiasi didefinisikan suatu proses untuk menemukan semua aturan assosiatif yang memenuhi syarat minimum untuk support (minimum support), dan syarat minimum untuk confidence (minimum confidence)[3].

Mencari sekumpulan item dengan algoritma apriori TID kita harus menggunakan tehnik association rule. Association role dinyatakan sebagai bentuk:

$$
\{\mathrm{A} \cap \mathrm{B}\} \rightarrow\{\mathrm{C}\} \text { Atau }\{\mathrm{A}, \mathrm{B}\} \rightarrow\{\mathrm{C}\}
$$

Selanjutnya, pengguna menentukan nilai minimum support dan minimum confidence yang akan digunakan dalam proses. Nilai minimum support dan minimum confidence yang dimasukkan yaitu antara $0-100 \%[1]$.

Support dari suatu association rules adalah proporsi dari transaksi dalam database yang mengandung A dan B, dapat di rumuskan sebagai berikut:

Support $(A \rightarrow B) \quad=P(A \cap B$

$$
=\underline{\text { jumlah transaksi yang mengandung } \mathrm{A} \text { dan } \mathrm{B}}
$$

Dimana

$$
\text { Jumlah total transaksi }
$$

$$
\text { Support }(\mathrm{A})=\frac{\text { jumlah transaksi mengandung } \mathrm{A}}{\text { Total transaksi }}
$$

Atau

Support $\left(\mathrm{A}^{1}, \mathrm{~A}^{2}, \ldots \mathrm{A}^{\mathrm{n}}\right)$

$=\underline{\text { Jumlah transaksi yang mengandung } \mathrm{A}^{1}, \mathrm{~A}^{2}, \ldots \mathrm{A}^{\mathrm{n}}}$

\section{Total transaksi}

Dan

Confindence $(\mathrm{A} \rightarrow \mathrm{B})=\mathrm{P}(\mathrm{B} \backslash \mathrm{A})$

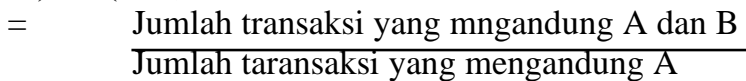

Seperti Algoritma apriori pada umumnya, Algoritma Apriori-TID juga menggunakan fungsi apriori-gen dalam menentukan kandidat itemset, tetapi perbedaanya terletak pada database yang tidak di gunakan dalam perhitungan support setelah lintasan pertama[10].

\subsection{Penjualan}

Penjualan merupakan suatu usaha yang terpadu untuk mengembangkan rencana-rencana strategis yang diarahkan pada usaha pemuasan kebutuhan dan keinginan pembeli, guna mendapatkan penjualan yang 
menghasilkan laba. Penjualan dapat dilakukan dengan berbagai cara, ada penjualan yang dilakukan secara tunai dan ada yang dilakukan secara kredit.Penjualan tunai dilakukan apabila barang yang diberikan oleh penjual langsung saat barang tersebut diterima dan ini sudah umum dilakukan juga dianggap sebagat penjulan yang lazim, dan penjualan yang dilakukan secara kredit adalah merupakan hal tagihan yang timbul dari transaksi penjualan barang atau jasa, dan merupakan komponen besar dalam aktiva lancar[1].

\subsection{Keramik}

Keramik pada awalnya berasal dari bahasa Yunani, keramikos, yang artinya suatubentuk dari tanah liat yang telah mengalami proses pembakaran. Kamus danensiclopedia tahun 1950-an mendefinisikan keramik sebagai suatu hasil seni danteknologi untuk menghasilkan barang dari tanah liat yang dibakar seperti gerabah,genteng, porselin, dan sebagainya. Tetapi saat ini tidak semua keramik berasal daritanah liat. Definisi pengertian keramik terbaru mencakup semua bahan bukanlogam dan anorganik yang berbentuk padat[11].

\section{ANALISA DAN PEMBAHASAN}

Penjualan keramik di PT. JUI SHIN INDONESIA Medan Deli belum tersusun dengan baik. Sehingga data penjualan keramik yang semakin lama semakin banyak tersebut hanya sebagai arsip bagi perusaahan dan tidak dapat dimamfaatkan perusaahan untuk pengembanagan strategi pengolahan data penjualan keramik yanag baik.

Tujuan analisa ini adalah untuk menjelaskan gambaran sistem pola penjualan keramik Oleh karena itu perusaahan membutuhkan sistem untuk mengolah data yang dapat menghasilkan data penjualan keamik yang dapat memprediksikan hasil penjualan disetiap tahunnya. Sehingga data-data penjualan keramik dapat dijadikan sebagai acuan untuk mrngrmbangkan strategi pemasaran dan dapat memprediksikan hasil penjualan ditahun berikutnya.

Pada sub ini merupakan gambaran proses analisa suatu masalah dan gambaran dari penerapan metode untuk memecahakan masalah penjualan di perusaahan. Untuk menunjang analisa, data dalam pencarian knowledge penulis mencoba mentransformasikan data. Data yang digunakan adalah data tarnsaksi penjualan keramik, di dalam data mining terdapat tehnik pengolahan data agar diolah lebih bermamfaat atau bernilai ilmu, salah satunya adalah asosiasi. langkah selanjutnya pembentukan rules yang akan dihasilkan dibentuk dari pola kombinsi itemset yang memenuhi support minimal. Flowchart algoritma apriori TID adalah suatu pembentukan pola kombinasi itemset yang memenuhi support minimal.

Adapun langkah langkah menentukan pola item dan jumlah item adalah:

1. Analisis data

Dengan studi kasus pada PT. JUI SHIN INDONESIA Medan Deli dapat dilakukan analisa terhadap data kasus data penjualan (data keramik keluar ) dengan salah satu tujuan adalah untuk menemukan pola kombinasi penjualan keramik dan hubungan antar item jenis keramik didalam ransaksi. Berikut ini adalah tabel 4.1 yaitu beberapa sampel data yanag akan dijadikan sampel untuk analisis dan juga pengujian.

Tabel 1. Tabel Data Penjualan keramik

\begin{tabular}{|c|c|c|}
\hline No & $\begin{array}{c}\text { Id } \\
\text { Transaksi } \\
\end{array}$ & Nama Item \\
\hline 1. & TF 011 & Keramik dinding polos, keramik embose monved \\
\hline 2. & TF 012 & Keramik embosed dasar dark tersia \\
\hline 3. & TF 013 & Keramik embosed premium tren, keramik standart polos, keramik dasar light lory \\
\hline 4. & TF 014 & $\begin{array}{l}\text { Keramik dasar medium sanderling, keramik laster light kurlew, keramik emboss } \\
\text { light grabe med, keramik laster Emboss dark darter med, keramik standart polos, } \\
\text { keramik Dinding polos }\end{array}$ \\
\hline 5. & TF 015 & Keramik embosed dasar dark tersia, keramik dinding polos \\
\hline 6. & TF 016 & Keamik embosed monved, keramik embosed premium tren Keramik satndart polos \\
\hline 7. & TF 017 & Keramik laster light kurlew, keramik dasar lory \\
\hline 8. & TF 018 & Keramik emboss light grabe med \\
\hline 9. & TF 019 & $\begin{array}{l}\text { Keramik laster emboss dark darter med, keramik standart Polos, keramik embosed } \\
\text { premium tren }\end{array}$ \\
\hline 10. & TF 020 & $\begin{array}{l}\text { Keramik embosed dasar dark tersia, keramik embosed monved, keramik dasar } \\
\text { medium sanderling, keramik standart polos }\end{array}$ \\
\hline 11. & TF 021 & keramik laster Emboss dark darter med, keramik dinding polos \\
\hline 12. & TF 022 & Keramik laster light kurlew, keramik dasar lorry, keramik dinding polos \\
\hline 13. & TF 023 & $\begin{array}{l}\text { keramik embosed premium tren, keramik standart polos, keramik dasar light lorry, } \\
\text { keramik emboss light grabe med, keramik dinding polos, }\end{array}$ \\
\hline 14. & TF 024 & $\begin{array}{l}\text { keramik standart polos, keramik dinding polos, keramik embosed premium tren, } \\
\text { keramik emboss light grabe med }\end{array}$ \\
\hline 15. & TF 025 & Keramik embosed dasar dark tersia, Keamik embosed monved, keramik embosed \\
\hline
\end{tabular}



16. TF 026
premium
17. TF 027
keramik dasar medium sanderling, Keramik laster light kurlew,
light grabe med, keramik standart polos, keramik dinding polos
17. $\mathrm{TF} 027$ keramik embosed premium trer
med, keramik standart polos,
18. TF 028
Keramik laster emboss dark
19. TF 029 premium tren
keramik standart polos
20. $\quad$ TF 30 keramik embosed premium, keramik emboss light grabe med,
21. TF 31 keramik dasar lorry

Data diatas adalah bentuk transaksi data penjualan (data keramik keluar) real terdiri atas attribute id transaksi dan nama keramik.

2. Merubah item menjadi bentuk variable Untuk memudahkan pengitungan jumlah jenis item yang dibeli oleh karena itu dilakukan suatu pembentukan variable untuk menggantikan jenis item tersebut seperti yang terlihat pada tabel 2

Tabel 2. Tabel Nama Item Keramik Dan Variabel

\begin{tabular}{llc}
\hline No & Nama Item & Variabel \\
\hline 1. & Keramik dinding polos & $\mathrm{A}$ \\
2. & Keramik embosed monved & $\mathrm{B}$ \\
3. & Keramik dasar dark tersia & $\mathrm{C}$ \\
4. & Keramik embosed premium tren & $\mathrm{D}$ \\
5. & Keramik satandart polos & $\mathrm{E}$ \\
6. & Keramik dasar medium sanderling & $\mathrm{F}$ \\
7. & Keramik dasar medium sanderling & $\mathrm{G}$ \\
8. & Keramik laster light curlew & $\mathrm{H}$ \\
9. & Keramik emboss light grabe med & $\mathrm{I}$ \\
10. & Keramik laster emboss dark darter med & J
\end{tabular}

3. Pola kombinasi item untuk mencari berapa jumlah item yang dibeli terhadap suatu jenis barang kemudian jumlah item tersebut digunakan mencari jumlah support minimum, seperti yang terlihat pada tabel 3.3 untuk menentukan item.

Tabel 3. Tabel Item Kombinasi

\begin{tabular}{lll}
\hline No & Id Transaksi & Variabel Kombinasi \\
\hline 1. & TF 011 & A,B \\
2. & TF 012 & C \\
3. & TF 013 & D,E,F \\
4. & TF 014 & G,H,I,J,E,A \\
5. & TF 015 & C,A \\
6. & TF 016 & B,D,E \\
7. & TF 017 & H,F \\
8. & TF 018 & I \\
9. & TF 019 & J,D,E \\
10. & TF 020 & C,B,G,E \\
11. & TF 021 & J,A \\
12. & TF 022 & H,A,I \\
13. & TF 023 & D,E,F,IA \\
14. & TF 024 & E,A,D,I \\
15. & TF 025 & B,C \\
16. & TF 026 & G,H,I,A,E \\
17. & TF 027 & D,A,I,E \\
18. & TF 028 & E,J,D \\
19. & TF 029 & I,B,A,E \\
20. & TF 030 & D,I \\
21. & TF 031 & F \\
\hline & &
\end{tabular}


4. Pencarian jumlah item support minimum Tabel dbawah merupakan pencarian jumlah item minimum support dan terdapat pada beberapa item yang terlihat pada tabel yang diberi warna biru yang merupakan hasil pencarian jumlah support minimum. contoh item yang mempunyai support minimum sebagai berikut:

Tabel 4. tabel item yang memenuhi support minimum

\begin{tabular}{cccc}
\hline No & Item & Jumlah & Support \\
\hline 1. & A & 10 & 50 \\
2. & B & 5 & 25 \\
3. & C & 4 & 20 \\
4. & D & 8 & 40 \\
5. & E & 11 & 55 \\
6. & F & 4 & 20 \\
7. & G & 3 & 15 \\
9. & I & 9 & 45 \\
10. & J & 4 & 20 \\
\hline
\end{tabular}

5. Asosiasi rule

Association rule mining merupakan salah satu teknik yang ada dalam penambangan data yang bertujuan untuk mendapatkan aturan asosiasi atau relasi antara sekumpulan item. Aturan asosiasi dapat diperoleh dari berbagai sumber data, di antaranya berasal dari basis data transaksional, gudang data, maupun dari tempat penyimpanan informasi yang lainnya. Kemudian pembentukkan rule, rule dibuat untuk kombinasi itemset yang memenuhi support minimum 30 seperti tabel 5.

Tabel 5. Tabel rule untuk kombinasi itemset yang memenuhi support minimum 25

\begin{tabular}{llll}
\hline No & Item Kombinasi & Jumlah & support \\
\hline 1. & A,I & 7 & 35 \\
2. & D,E & 7 & 35 \\
3. & A,E & 6 & 30 \\
\hline
\end{tabular}

Tabel 6. Tabel transaksi penjualan kombinasi 2 item

\begin{tabular}{|c|c|c|c|c|}
\hline No & Contoh Item yang dibeli & Support Item Acedent & Support Item & confident \\
\hline 1. & Jika dibeli A maka dibeli I & 50 & 35 & 70 \\
\hline 2. & Jika dibeli I maka di beli A & 45 & 35 & 77.77778 \\
\hline 3. & Jika dibeli D maka di beli $\mathrm{E}$ & 55 & 35 & 87.5 \\
\hline 4. & Jika dibeli E maka di beli $\mathrm{D}$ & 55 & 35 & 63.63636 \\
\hline 5. & Jika dibeli A maka dibeli $\mathrm{E}$ & 50 & 30 & 60 \\
\hline 6. & Jika dibeli E maka dibeli A & 40 & 30 & 75 \\
\hline
\end{tabular}

Tabel diatas merupakan contoh kasus pertama transaksi penjualan kombinasi 2 item untuk mendapatkan nilai confident.

Tabel 7. Tabel transaksi penjualan kombinasi 3 item AI,E

\begin{tabular}{lllll}
\hline No & Contoh Item yang dibeli & Support item Acedent & Support Item & confident \\
\hline 1. & Jika dibeli A, maka dibeli I dan E & 50 & 30 & 60 \\
2. & Jika dibeli I dan E, maka dibeli A & 30 & 30 & 100 \\
3. & Jika dibeli A dan E maka dibeli I & 30 & 30 & 100 \\
4. & Jika dibeli I maka dibeli Adan E & 45 & 30 & 66.66667 \\
5. & Jika dibeli A dan I maka dibeli E & 35 & 30 & 85.71429 \\
6. & Jika E maka dibeli A dan I & 40 & 30 & 75 \\
\hline
\end{tabular}

Tabel diatas merupakan contoh kasus kedua transaksi penjualan kombinasi 3 item untuk mendapatkan nilai confident.

\section{IMPLEMENTASI}

Implementasi untuk mengetahui pola penjualan keramik yang terdapat pada transaksi penjualan keramik berbentuk sebuah sistem aplikasi Tanagra 1.4. Adapun hasil pengujianya seperti dibawah ini:

1. Tampilan Mikrosoft Exel 2007

Dalam sistem ini diperlukan untuk pengimputan data awal sebelum membuka aplikasi Tanagra 4.1 setelah itu disimpan ke Mikrosoft Exel 2000. berikut ini merupakan data transaksi penjualan keramik yang terdapat pada gamabar 1. dibawah ini: 


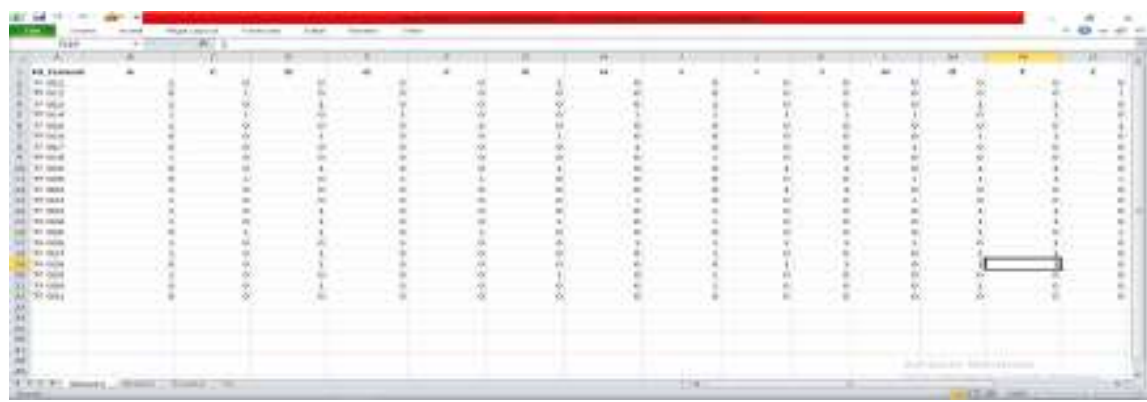

Gambar 1. Mikrosoft Exel 2007

2. Tampilan Form Menu Utama Tanagra 1.4

Pada tampilan form menu utama ini adalah bentuk atau gambaran sistem penyimpanan file yang terdapat pada gambar 2. dibawah ini:

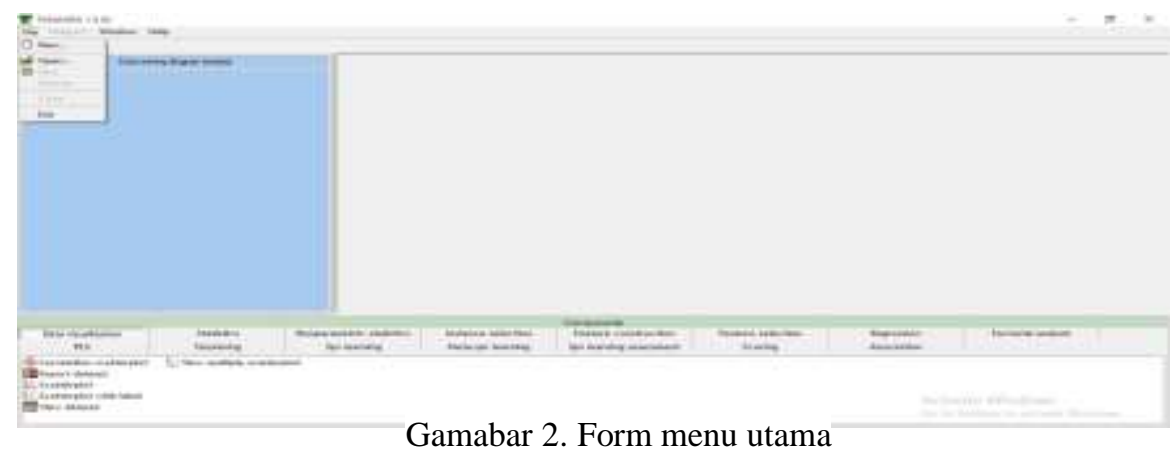

3. Tampilan form input dataPada bagian tampilan proses pengimputan data adalah tampilan pegimputan data dari Mikrosoft Exel 2000 ke Aplikasi Tanagra 1.4 yang terdapat pada gambar 3. di bawah ini:

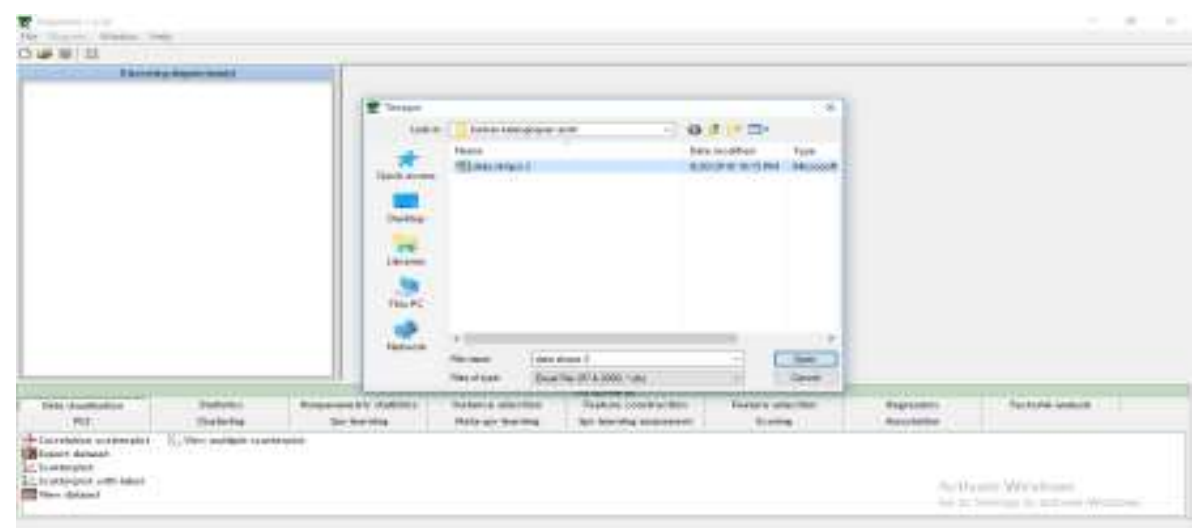

Gamabar 3. tampilan form input data

4. Form menu tampilan barang terimput

Pada bagian tampilan ini dalah tampilan data transaksi penjualan keramik yang sudah terimputterdapat pada gambar 4. di bawah ini:

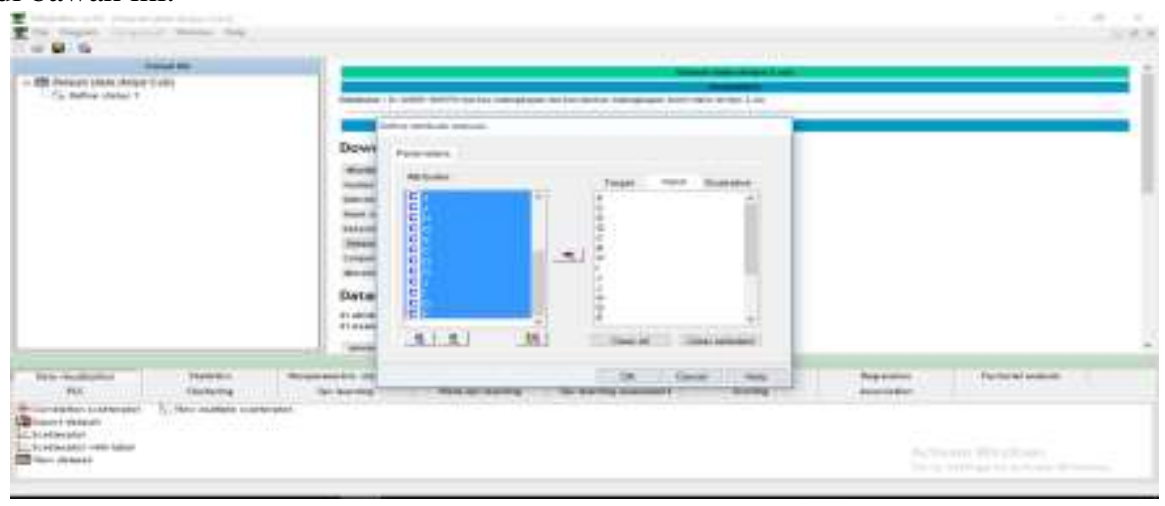

Gambar 4. form barang terimput 
5. Form menu minimum support 25

Pada bagian tampilan ini adalah tampilan data transaksi yang memenuhi support minimum support 25 dengan menggunakan tehnik Association seperti yang terdapat pada gambar 5. di bawah ini:

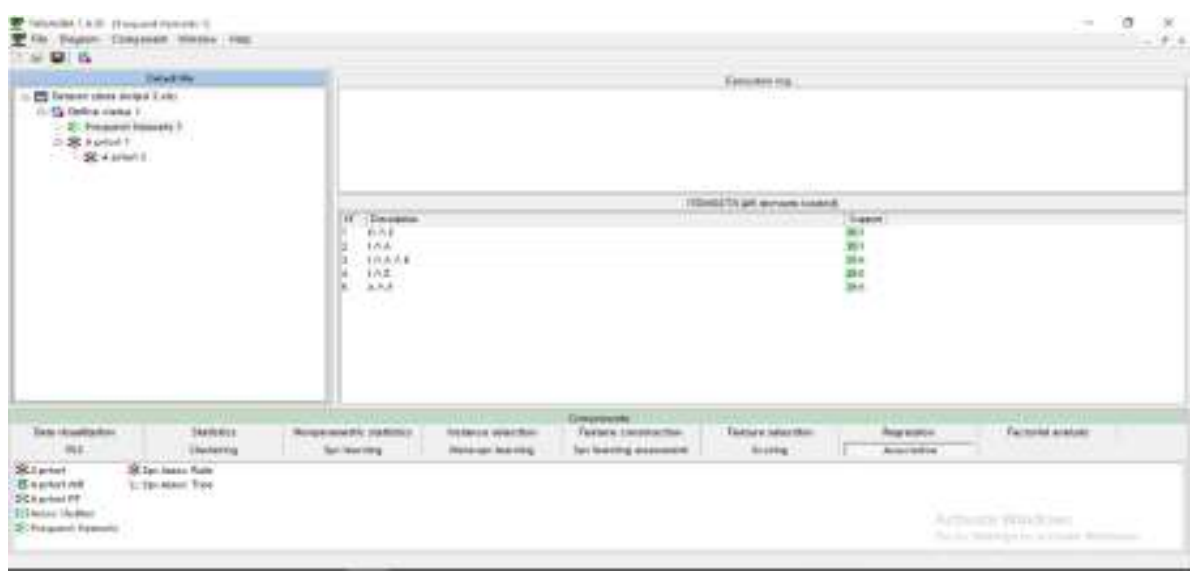

Gambar 5. form menu support 25

6. Form menu rule

Pada bagian tampilan ini adalah tampilan jumlah keseluruhan item barang seperti yang terdapat pada gambar 6 . di bawah ini:

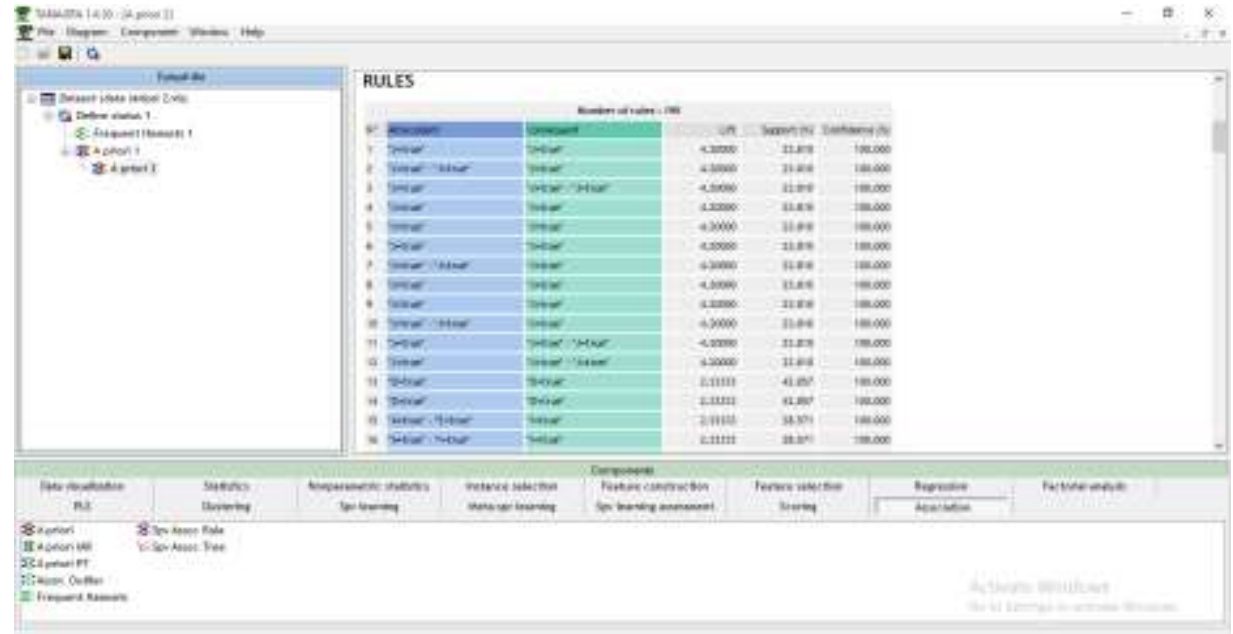

7. Form menu keluar

Gambar 6. form menu rule

Pada tampilan ini adalah tampilan keluar dari aplikasi seperti yang terlihat pada gamabar 5.7 di bawah ini:

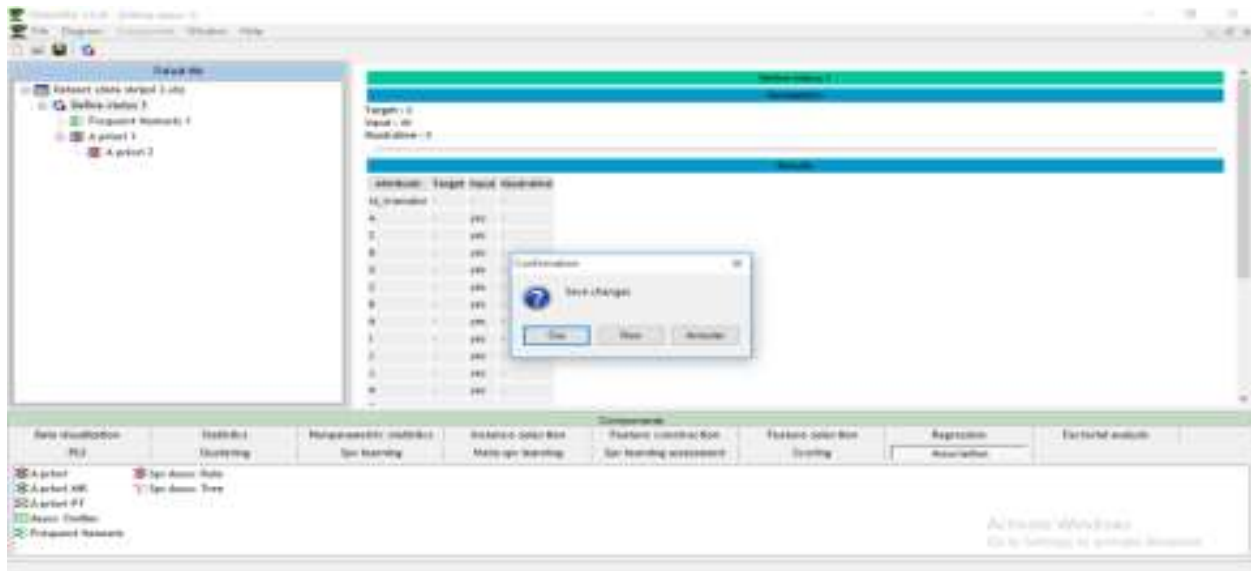

Gambar 7. form menu keluar 


\section{KESIMPULAN}

Adapun kesimpulan yang dapat diambil berdasarkan penelitian ini adalah sebagi berikut:

1. Untuk mengetahui pola penjualan keramik pada PT. JUI SHIN INDONESIA kita harus menganalisisdata berukuran besar untuk menemukan hubungan antar data supaya menghasilkan informasi untuk pengguna data tersebut.

2. Adapun cara mengimplementasikan algoritma apriori TID di PT. JUI SHIN INDONESIA yaitu melakukan pencarian sekolompok item yang memenuhi support yang lebih besar dari support minimum yang ditentukan dengan menggunakansekelompok besar itemset, untuk membangkitkan yang memiliki nilai cofidance.

3. Untuk menggunakan aplikasi Tanagra 1.4 yaitu terlebih dahulu kita menginstalnya di komputer kita kemudian setelah terinsttal baru kita membuka aplikasi terebut seterusnya kita terlebih dahulu membuka data kita di Mikrosoft Exel 2007 dan setelah itu menyimpan nya di Mikrosoft Exel 2000 sebagai database yang digunakan untuk melakaukan pengujian data.

\section{REFERENCES}

[1] "Rancang Bangun Sistem Informasi Penjualan Barang (Studi Kasus: U.D Cendana Depok Townsquare),” J. Sist. Inf., vol. 4, no. $1,2012$.

[2] T. K. I. A, "ALGORITMA ATURAN ASOSIASI APRIORI-TID DENGAN METODE KLASTERISASI HIERARKI AGLOMERATIF Tri Khairul I.A 1 1.," pp. 1-5.

[3] R. Purbaningtyas, A. Arizal, and T. Wardoyo, "PENERAPAN ALGORITMA APRIORI TID SEBAGAI METODE OPTIMASI PENCARIAN DATA PADA APLIKASI MOBILE SIDOARJO on HANDS (SoH)," J. Penelit. Pos dan Inform., vol. 7, no. 2, p. 87, 2017.

[4] M. Tanjung, "Fungsi Organisasi dalam Manajemen Proyek," Manaj. dan Inform. Komput. Pelita Nusant., vol. 1, no. Juli, p. $5,2017$.

[5] E. Buulolo, "Implementasi Algoritma Apriori Pada Sistem Persediaan Obat ( Studi Kasus : Apotik Rumah Sakit Estomihi Medan )," pp. 71-83, 2013.

[6] H. Widayu, S. Darma, N. Silalahi, and Mesran, "Data Mining Untuk Memprediksi Jenis Transaksi Nasabah Pada Koperasi Simpan Pinjam Dengan Algoritma C4.5," Issn 2548-8368, vol. Vol 1, No, no. June, p. 7, 2017.

[7] V. N. Latifah, M. T. Furqon, and N. Santoso, "Implementasi Algoritme Modified-Apriori Untuk Menentukan Pola Penjualan Sebagai Strategi Penempatan Barang Dan Promo,” J. Pengemb. Teknol. Inf. dan Ilmu Komput. Univ. Brawijaya, vol. 2, no. 10, pp. 2829-2834, 2018.

[8] D. T. Larose and D. T. Larose, Data Mining Methods $\backslash \&$ Models. 2006.

[9] J. Nanosains, "Sintesis Keramik Berbasis Komposit Clay-Karbon dan Karakterisasi Kekuatan Mekaniknya," vol. 2, no. 2, 2009.

[10] Fadlina, "Data Mining Untuk Analisa Tingkat Kejahatan Jalan Dengan Algoritma Association Rule Metode Apriori,” Maj. Ilm. Inf. dan Teknol. Ilm., vol. III, pp. 144-154, 2014. 